\title{
Group II and III Metabotropic Glutamate Receptors Suppress Excitatory Synaptic Transmission in the Dorsolateral Bed Nucleus of the Stria Terminalis
}

\author{
Brad A Grueter' and Danny G Winder, ${ }^{*, 1,2}$ \\ 'Department of Molecular Physiology and Biophysics, Vanderbilt University School of Medicine, Nashville, TN, USA; ${ }^{2}$ Center for Molecular \\ Neuroscience, Vanderbilt University School of Medicine, Nashville, TN, USA
}

\begin{abstract}
Conditions such as anxiety, drug abuse, and post-traumatic stress disorder are thought to reflect alterations in central nervous system stress and reward circuitry. Recent evidence suggests a key component of this circuitry is the bed nucleus of the stria terminalis (BNST). In particular, regulation of glutamatergic transmission in the BNST plays a critical role in animal performance on anxiety tasks. Metabotropic glutamate receptors (mGluRs) have been implicated in stress and drug addiction and are known to regulate glutamatergic transmission in many brain regions. We have utilized both extracellular field potential and whole-cell patch-clamp recording in an in vitro slice preparation of mouse dorsal anterolateral BNST to determine whether $\mathrm{G}_{\mathrm{i} / \mathrm{o}}$-linked mGluRs modulate excitatory transmission in this region. We find that activation of group II and group III mGluRs in an in vitro slice preparation of the dBNST causes a depression of excitatory transmission. The depression evoked by group II mGluR activation may represent a form of synaptic plasticity as prolonged activation of the receptor produces a long-term depression of glutamatergic transmission. Based on paired-pulse ratio analysis, initiation of depression by group II and group III mGluR subfamilies appears to, at least in part, involve decreased glutamate release. In total, our data suggest a plausible site of action for some of the anxiolytic effects of group II and group III mGluR agonists.

Neuropsychopharmacology (2005) 30, I302-131I, advance online publication, 6 April 2005; doi: I0.1038/sj.npp. 1300672
\end{abstract}

Keywords: anxiety; addiction; mGluRs; bed nucleus of the stria terminalis; long term depression; excitatory transmission

The bed nucleus of the stria terminalis (BNST) is a key intermediary in the stress response pathway of the brain, and in the integration of stress and reward pathways (Herman and Cullinan, 1997; Delfs et al, 2000; Shaham et al, 2000). The BNST receives glutamatergic input from the ventral subiculum, the limbic cortex and the basal lateral amygdala (BLA) (Walker et al, 2003), as well as dense neuromodulatory inputs from the noradrenergic, serotonergic and dopaminergic pathways (Phillipson, 1979; Phelix et al, 1992). The BNST sends a number of projections to regions comprising the central autonomic control system, as well as reward circuitry (Phillipson, 1979; Dong and Swanson, 2004). For example, the BNST sends projections to the paraventricular nucleus of the hypothalamus (PVN)

\footnotetext{
*Correspondence: Dr DG Winder, Department of Molecular Physiology and Biophysics, Vanderbilt University School of Medicine, 724B Robinson Research Building, 23rd and Pierce Ave., Nashville, TN 37232-06 15, USA, Tel: + | 615322 ||44, Fax: + I 615322 1462, E-mail: danny.winder@vanderbilt.edu

Received 15 September 2004; revised 10 November 2004; accepted 10 December 2004

Online publication: 16 December 2004 at http://www.acnp.org/citations/ NPP I 2 1604040425/default.pdf
}

to regulate hormonal corticotrophin releasing factor (CRF) release, pituitary activation and ultimately, the stress response. Further, the BNST monosynaptically regulates the ventral tegmental area (VTA) (Georges and Aston-Jones, 2002).

Consistent with its interconnections with the BLA and the PVN, the BNST plays a critical role in anxiety (Davis et al, 1997; Herman and Cullinan, 1997; Walker et al, 2003). Inhibition of fast excitatory transmission in the BNST by injection of an AMPA receptor antagonist blunts anxiety responses (Walker and Davis, 1997), suggesting that regulation of glutamatergic transmission in this region may be an important target for anxiolytic and anxiogenic stimuli. Therefore, a detailed understanding of the mechanisms involved in the regulation of glutamatergic transmission in the BNST could lead to the development of novel anxiolytic therapeutics.

Metabotropic glutamate receptors (mGluRs) are Gprotein coupled receptors that modulate glutamatergic synaptic transmission in a number of different brain regions. Eight known subtypes of mGluRs are classified into three groups based on pharmacology, effector coupling mechanisms, and sequence homology. Group I receptors (mGluR1 and mGluR5) are linked to $\mathrm{G}_{\mathrm{q}}$, whereas, group II 
(mGluR2 and mGluR3) and group III (mGluR4, mGluR6, mGluR7, and mGluR8) mGluRs are coupled to $G_{i / o}$ (for reviews, see Conn and Pin, 1997; Anwyl, 1999).

Behavioral studies, both in rodent models of anxiety (Helton et al, 1998; Klodzinska et al, 1999; Linden et al, 2002; Tizzano et al, 2002; Linden et al, 2003) and in humans (Grillon et al, 2003; Schoepp et al, 2003), suggest that group II and III mGluR ligands may represent useful approaches to treat anxiety. These receptors regulate glutamatergic transmission in several different brain regions, in many cases inhibiting transmission (Heinbockel and Pape, 2000; Lin et al, 2000; Kahn et al, 2001; Otani et al, 2002; Robbe et al, 2002), and in other cases enhancing trans mission (Evans et al, 2000; Rush et al, 2001; Wu et al, 2004). Group II and III mGluRs have been shown to function in brain regions involved in stress responses. For instance, group II mGluRs provide tonic regulation of glutamatergic transmission in the hypothalamic-pituitaryadrenocortical (HPA) axis (Scaccianoce et al, 2003) and inhibition of glutamatergic transmission in the PFC (Otani et al, 2002), Group III mGluRs induce a long-lasting potentiation of glutamatergic transmission in the BLA (Neugebauer et al, 1997) and inhibit glutamatergic transmission in the PVN (Schrader and Tasker, 1997). Both group II and group III mGluRs have been shown to inhibit glutamatergic transmission in the central nucleus of the amygdala (Neugebauer et al, 2000), and hippocampus (Capogna, 2004).

Immunohistochemical studies suggest expression of mGluR2, mGluR3 (Ohishi et al, 1998; Tamaru et al, 2001), and mGluR7 in the BNST (Kinoshita et al, 1998) as well as mRNAs for mGluR7 but not mGluR4 (Kinzie et al, 1995; Ohishi et al, 1995). To date, the actions of mGluRs on glutamatergic transmission in the BNST have not been reported. Therefore, we utilized two distinct electrophysiological methods, extracellular field potential and whole-cell patch-clamp recordings, to determine the effect of activation of group II and group III mGluRs on excitatory transmission in BNST. We find that both group II and group III mGluRs elicit a long-lasting inhibition of excitatory synaptic transmission in the BNST.

\section{MATERIALS AND METHODS}

\section{Brain Slice Preparation}

Male C57B16/j mice (6-10 weeks old, Jackson Laboratories) were decapitated under anesthesia (Isoflurane). For interface chamber recordings, the brains were quickly removed and placed in ice-cold artificial cerebro-spinal fluid (ACSF) (in mM: $124 \mathrm{NaCl}, 4.4 \mathrm{KCl}, 2 \mathrm{CaCl}_{2}, 1.2 \mathrm{MgSO}_{4}, 1 \mathrm{NaH}_{2} \mathrm{PO}_{4}$, 10 glucose, and $26 \mathrm{NaHCO}_{3}$ ). Slices $300 \mu \mathrm{m}$ in thickness were prepared using a vibratome (Leica). Rostral slices containing anterior portions of BNST (bregma $0.26 \mathrm{~mm}$ to $0.02 \mathrm{~mm}$ ) (Franklin and Paxinos, 1997) were identified using the internal capsule, anterior commissure, fornix, and stria terminalis as landmarks as previously described (Egli and Winder, 2003; Egli et al, in press; Weitlauf et al, 2004). Slices were then transferred to either an interface recording chamber (field potential recordings, $\sim 28^{\circ} \mathrm{C}$ ), a submerged recording chamber (whole-cell patch-clamp recordings, 24$25^{\circ} \mathrm{C}$ ), or a submerged holding chamber $\left(25^{\circ} \mathrm{C}\right)$ where they were perfused with oxygenated $\left(95 \% \mathrm{O}_{2} / 5 \% \mathrm{CO}_{2}\right)$ ACSF at a rate of $2 \mathrm{ml} / \mathrm{min}$. Slices were allowed to equilibrate in normal ACSF for $1 \mathrm{~h}$ before experiments began.

\section{Extracellular Field Recordings}

Low-resistance (2-3 M $\Omega$ ) extracellular electrodes were pulled with borosilicate glass on a Flaming-Brown Micropipette Puller (Sutter) and were filled with ACSF. Stimulating electrodes consisted of twisted, insulated nichrome bipolar wire. Stimulating electrodes were placed on the dorsal anterolateral BNST (dBNST) border of the internal capsule approximately $200-500 \mu \mathrm{m}$ dorsal to the anterior commissure. Field potential responses were evoked at a frequency of $0.05 \mathrm{~Hz}$ using a stimulus range of $5-15 \mathrm{~V}$ at a duration of $100-150 \mu \mathrm{s}$. Experiments were performed in a heated $\left(\sim 28^{\circ} \mathrm{C}\right)$ interface-style recording chamber (Fine Science Tools) as previously reported (Weitlauf et al, 2004; Egli et al, in press). All recordings were performed in the presence of $25 \mu \mathrm{M}$ picrotoxin. Data points are represented as averages of the peak amplitude at $1 \mathrm{~min}$ intervals.

\section{Whole-Cell Voltage-Clamp Recordings}

Slices were prepared as above except the dissection solution was a low $\mathrm{Na}^{+} /$high sucrose solution. Recordings were performed in a submerged chamber continuously perfused at a rate of $2 \mathrm{ml} / \mathrm{min}$ with oxygenated ACSF $\left(24-25^{\circ} \mathrm{C}\right)$. Electrodes of 3.0-5.0 M $\Omega$ were pulled on a Flaming-Brown Micropipette Puller and were filled with (in $\mathrm{mM}$ ): $\mathrm{K}^{+}$ gluconate or Cs gluconate (135), $\mathrm{NaCl}$ (5), HEPES (10), EGTA (0.6), ATP (4), GTP (0.4), and biocytin (0.1\%). Effects of mGluR ligands on glutamatergic transmission obtained with these two internal solutions were comparable and therefore pooled. All cells recorded from were voltageclamped at $-70 \mathrm{mV}$. Excitatory post-synaptic currents (EPSCs) of $100-400 \mathrm{pA}$ were acquired by a Multiclamp amplifier (Axon Instruments), digitized and analyzed via pClamp 9.0 software (Axon Instruments). Input resistance

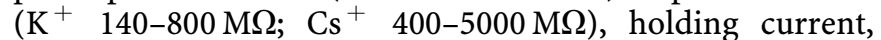
and access resistance (12-45 M $\Omega$ ) were all monitored continuously throughout the duration of the experiments (see Figure 4a). Experiments in which changes in access resistance were greater than $20 \%$ were not included in the data analysis. Stimulating electrodes and their placement were identical to field potential recordings. Stimulus intensity ranged from 6 to $30 \mathrm{~V}$ with $100 \mu \mathrm{s}$ duration. Events were recorded at a frequency of $0.17 \mathrm{~Hz}$. Data are represented as a $1 \mathrm{~min}$ average of the peak amplitudes.

\section{Drug Application}

All experiments were performed in the presence of picrotoxin $(25 \mu \mathrm{M})$. Where indicated in the text, the following drugs were bath applied. Tetrodotoxin (TTX, $1 \mu \mathrm{M})$ and 6-cyano-7-nitroquinoxaline-2,3-dione disodium salt (CNQX, $10 \mu \mathrm{M})$ were purchased from Sigma-Aldrich (St Louis, MO). (2S, $\left.2^{\prime} R, 3^{\prime} R\right)-2-\left(2^{\prime}, 3^{\prime}\right.$-dicarboxycyclopropyl)glycine (DCG-IV, $1 \mu \mathrm{M})$, L- $(+)$-2-amino-4-phosphonobytyric acid (L-AP4), DL-2-amino-5-phosphonovaleric acid (APV, 
$10 \mu \mathrm{M}),(2 S)$-2-amino-2-[(1S,2S)-2-carboxycycloprop-1-yl]3-(xanth-9-yl) propanoic acid, (LY341495, $1 \mu \mathrm{M})$, and $(S)$ 3,4-dicarboxyphenylglycine (DCPG, $30 \mu \mathrm{M})$ were purchased from Tocris. Dimethyl sulfoxide (DMSO) was the carrier for picrotoxin $(0.02 \% \mathrm{v} / \mathrm{v})$. ( $1 S, 2 S, 5 R, 6 S)$-2-aminobicyclo [3.1.0]hexane-2,6-dicarboxylic acid (LY 354740) was a gift from Dr Darryle Schoepp (Eli Lilly).

\section{RESULTS}

\section{Local Stimulation in the dBNST Yields an Excitatory Response}

Consistent with previous results (Weitlauf et al, 2004; Egli et al, in press), as shown in Figure 1, brief, local, singlepulse stimulation (50-100 $\mu \mathrm{s})$ in dBNST from 6-10-weekold male C57B16/J mice yields a short latency extracellular waveform in an interface chamber, which typically includes a biphasic negative potential in the presence of $25 \mu \mathrm{M}$ picrotoxin (Figure 1a, b). The first downward deflection (referred to as N1) of the biphasic peak is abolished by the sodium channel blocker, TTX $(1 \mu \mathrm{M})$ (Figure 1a). Thus, the $\mathrm{N} 1$ is thought to be indicative of an axonal response and to reflect the number of axons/cells directly stimulated in the field. The second peak (referred to as N2) also is abolished by TTX, but in addition is sensitive to CNQX, an AMPA/ kainate receptor antagonist, suggesting that it is driven by excitatory glutamatergic transmission (Figure $1 \mathrm{~b}$ ).
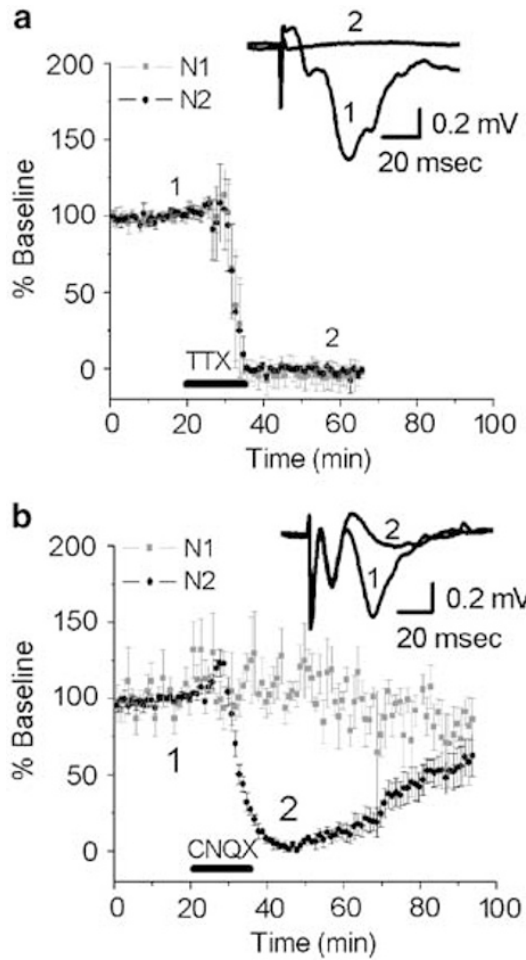

Figure I Characterization of field potential responses in BNST. (a) Time course of the effects of TTX (I $\mu M$ for I 5 min, $n=5)$ on the $N I$ and $N 2$ of the BNST field potential. Inset, representative traces of a BNST field potential pre- and post-TTX $(\mid \mu \mathrm{M})$ application. (b) Time course of the effects of CNQX (I0 MM for $15 \mathrm{~min}, n=6)$ on the $\mathrm{NI}$ and $\mathrm{N} 2$ of the BNST field potential. Inset, representative traces of a BNST field response pre- and post-CNQX (I0 $\mu \mathrm{M})$ application.
Whole-cell patch-clamp recordings were acquired in cells from the same region of the $\mathrm{dBNST}$ as the field potential recordings in a submerged chamber. Current-voltage relationships obtained from these neurons (Figure 2a) are consistent with those previously reported (Rainnie, 1999; Egli and Winder, 2003). Synaptic stimulation in the presence of $25 \mu \mathrm{M}$ picrotoxin, at a holding potential of $-70 \mathrm{mV}$ elicited an excitatory postsynaptic current (EPSC, Figure 2b). This EPSC had a reversal potential of near $0 \mathrm{mV}$ when corrected for junction potential (Figure 2b), was stable for long periods of time (Figure 2c), and was abolished by CNQX at $-70 \mathrm{mV}$ (Figure 2d). The EPSC under basal stimulation is unaltered in the presence of the NMDA antagonist DL-AP5 (data not shown). These data indicate that the postsynaptic currents elicited by a brief stimulus are primarily mediated by non-NMDA glutamate receptor subtypes.

\section{Group II mGluR Activation Inhibits Excitatory Field Potentials in the dBNST}

To determine the role of activation of group II mGluRs on excitatory synaptic transmission in dBNST, we assessed the effects of application of specific group II mGluR agonists on both the extracellular N2 response and the EPSC. To evaluate the effect of group II mGluR activation on the CNQX-sensitive N2 potential in dBNST slices, the group II mGluR agonist LY354740 ( $1 \mu \mathrm{M}$ for $15 \mathrm{~min})$ was bath applied in an interface recording chamber. LY354740 caused a transient, reversible depression of the field potential to $74.8 \pm 4.7 \%$ of baseline that was not associated with any changes in the $\mathrm{N} 1$ response (Figure $3 \mathrm{a}$ ). This action was blocked by pretreatment of the slice with the mGluR antagonist LY341495 (1 $\mu \mathrm{M}$, Figure 3b), which had no effect on basal transmission when applied alone (data not shown). Furthermore, the effect of LY354740 on field recordings was mimicked by another selective group II mGluR agonist DCG-IV. Perfusion of DCG-IV $(1 \mu \mathrm{M}, 15 \mathrm{~min}$, in presence of DL-APV to block potential direct actions of the drug at NMDA receptors ) caused a reversible depression of the N2 amplitude to $70.0 \pm 3.6 \%$ of baseline (Figure $3 \mathrm{c}$ ).

\section{Group II mGluR Activation Inhibits Synaptically Evoked EPSCs in the dBNST in a Dose-Dependent Manner}

The inhibition of the field potential response observed above could be through mGluRs acting at a number of different levels. To more specifically isolate glutamatergic synaptic transmission, we determined the effect of activation of group II mGluRs on voltage-clamped EPSCs. Similar to field potential results described above, brief perfusion of LY354740 ( $1 \mu \mathrm{M}$ for $5 \mathrm{~min}$ ) during whole-cell voltage-clamp recordings of dBNST neurons caused a transient depression of EPSCs. Peak depression was $53.4 \pm 3.9 \%$ of baseline (Figure 4a, b). The LY354740 elicited inhibition of EPSC amplitude returned to baseline levels approximately $30 \mathrm{~min}$ post washout. As shown in representative fashion in Figure $4 \mathrm{a}$, this depression of the EPSC was not associated with marked changes in the holding current or input resistance $(\mathrm{Rm})$. LY354740-induced suppression of EPSCs was concentration-dependent, with an $\mathrm{EC}_{50}$ of $\sim 6.0 \mathrm{nM}$ (Figure 4c). 


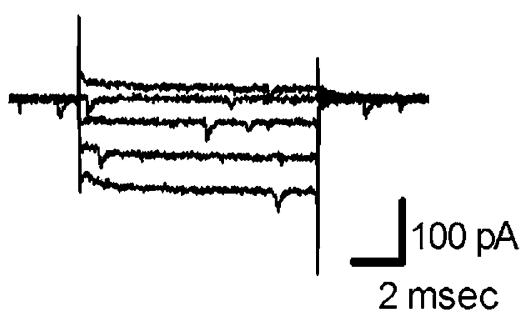

C

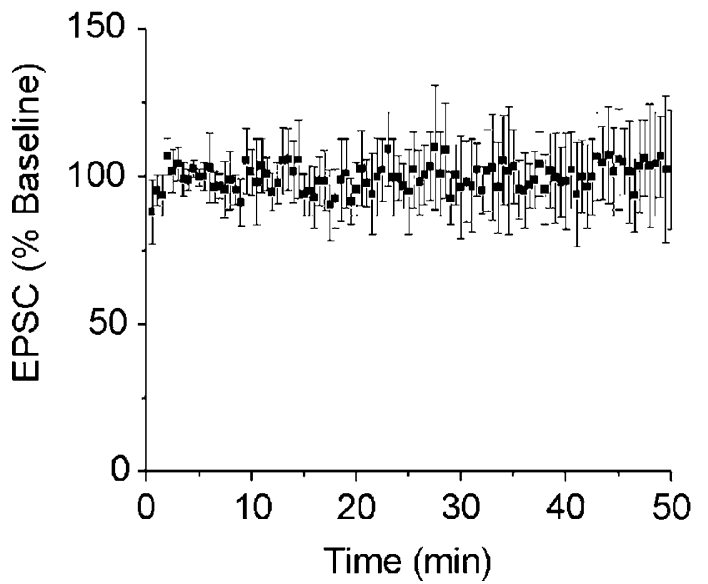

b

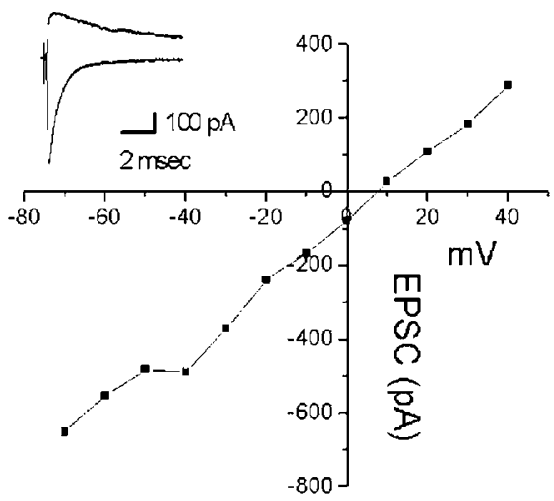

d

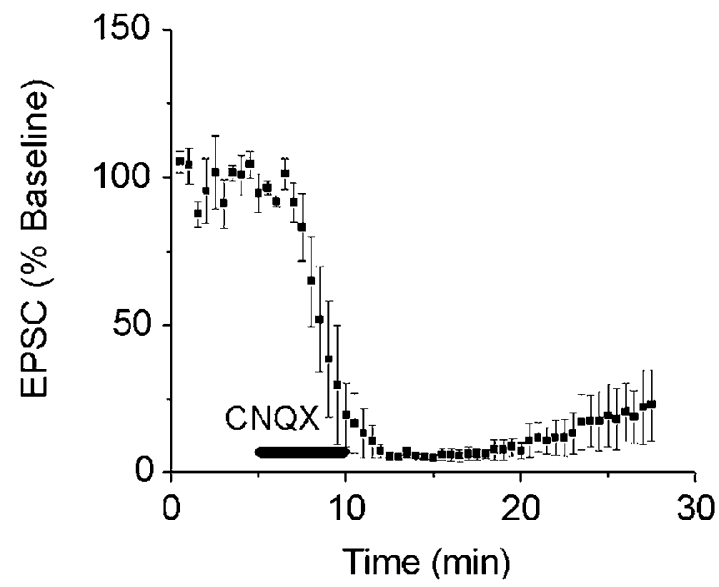

Figure 2 Characterization of synaptically evoked EPSCs in the BNST. (a) Representative trace of an I-V relationship of a BNST neuron. Cell was voltage clamped at $-70 \mathrm{mV}$ and stepped in $10 \mathrm{mV}$ intervals from -100 to $-20 \mathrm{mV}$. Scale indicates $100 \mathrm{pA}$ and $2 \mathrm{~ms}$. (b) $1-V$ plot of EPSC. Inset represents traces at -70 and $+40 \mathrm{mV}$. (c) Stability of evoked EPSCs in the BNST $(n=4)$. (d) Time course of effects of CNQX on EPSCs in the BNST $(n=3)$.
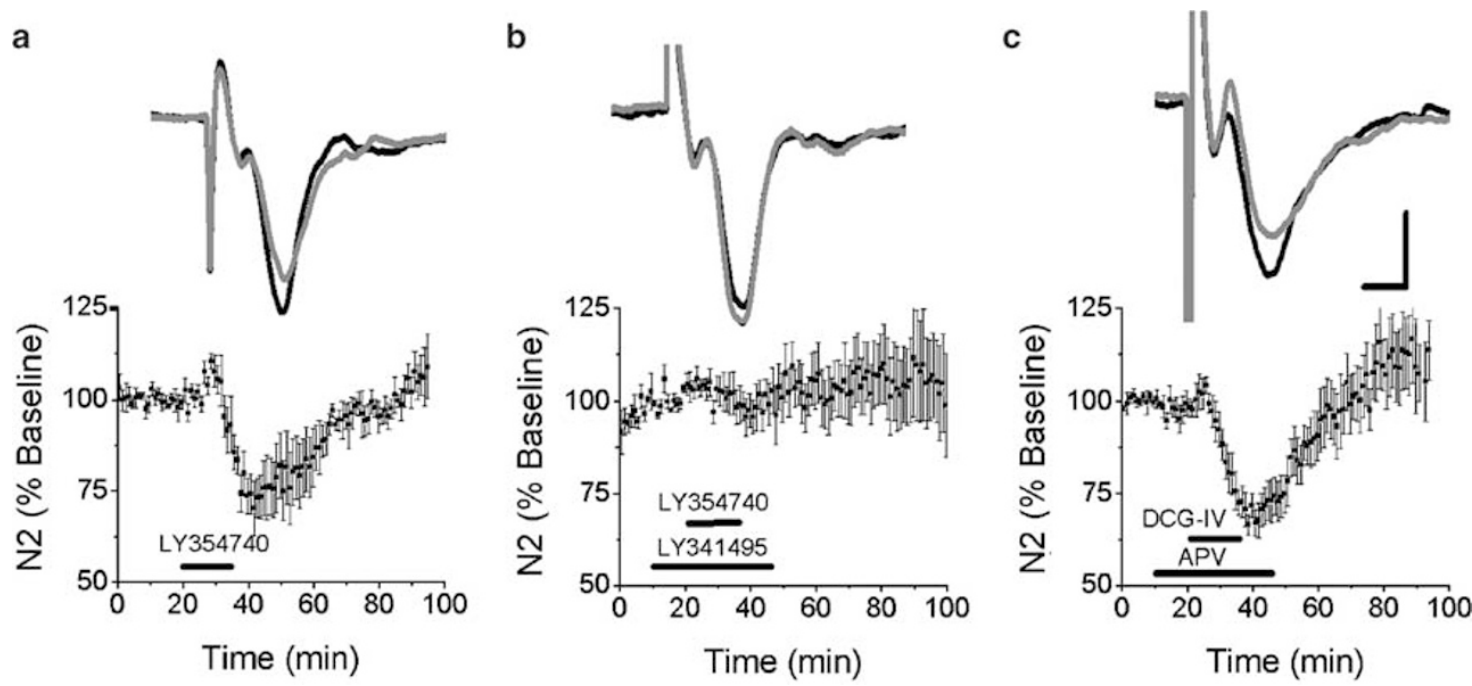

Figure 3 Group II activation depresses synaptic field potentials in the BNST. Time course of effects of group II mGluR compounds on excitatory transmission in the BNST. (a) LY354740 ( $1 \mu \mathrm{M}, 15 \mathrm{~min}, n=5$ ) significantly reduced field potential amplitude in the BNST. The effects of LY354740 were completely reversible 30 min following washout. (b) The effects of LY354740 (I $\mu$ M) were blocked by LY34|495 (I $\mu$ M LY34|495, $n=5$ ). (c) DCG-IV ( I $\mu \mathrm{M}, 15 \mathrm{~min}$, in presence of $100 \mu \mathrm{M}$ AP-5, $n=5$ ) also inhibits $\mathrm{N} 2$ responses. Scale indicates $0.2 \mathrm{mV}$ and $20 \mathrm{~ms}$.

Similar to field potential effects, LY341495 $(1 \mu \mathrm{M})$ blocked the depression of EPSCs induced by LY354740. In the presence of LY341495, the depression induced by LY354740 was $101.3 \pm 10.1 \%$ of baseline (Figure $4 \mathrm{~d}$ ). These results suggest that a group II mGluR inhibits excitatory transmission in the dBNST. 

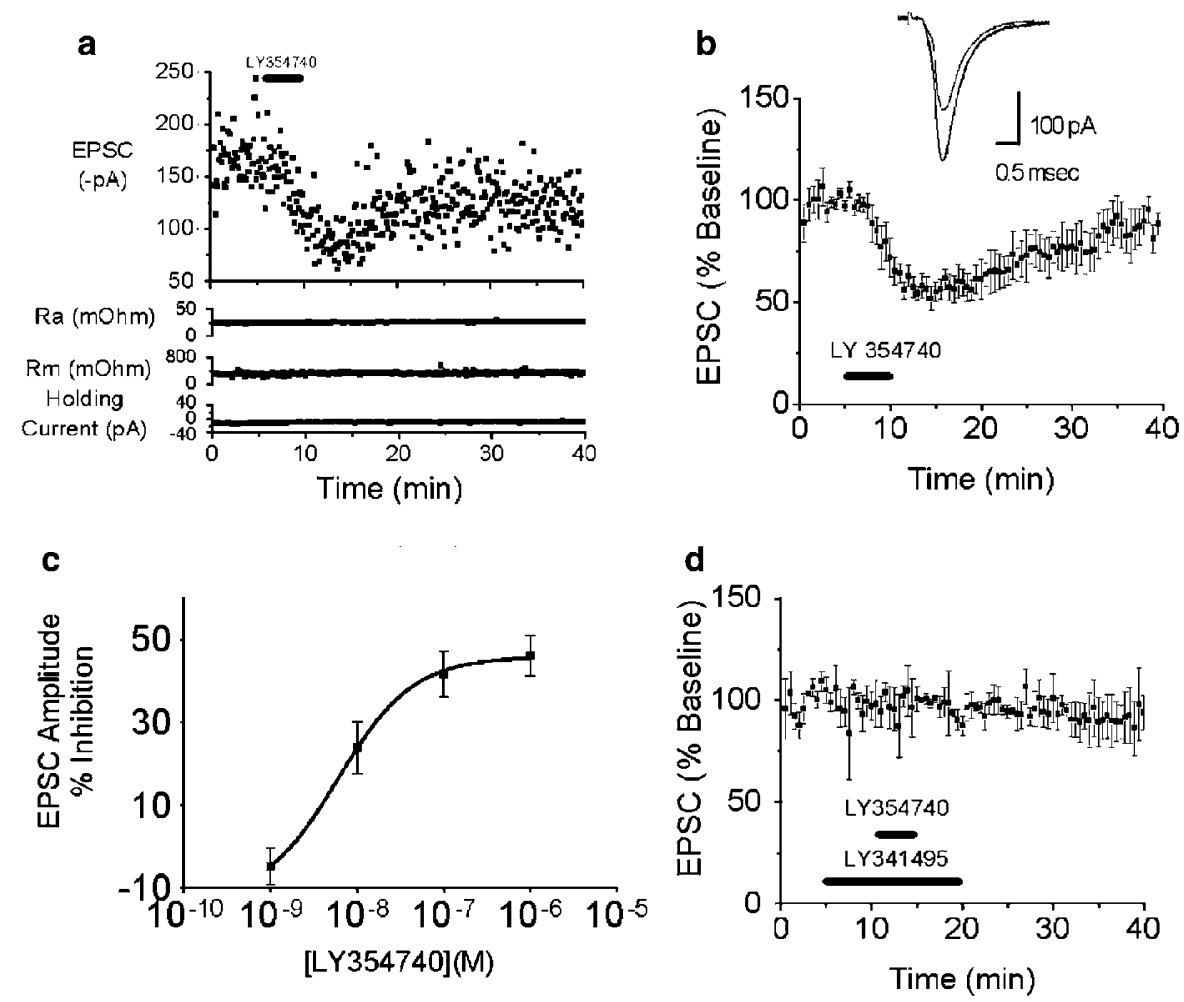

Figure 4 Inhibition of EPSCs in BNST neurons by activation of group II mGluRs is concentration dependent. (a) Representative experiment illustrating the lack of postsynaptic effects and the depression of excitatory synaptic transmission by LY354740 (I $\mu$ M, 5 min). (b) Average results of 5 min application of LY354740 ( $n=6)$. (c) Depression of synaptic transmission by LY354740 is concentration dependent $(n=3-6)$. (d) The effects of LY354740 were blocked by LY34I495 ( $n=3)$.

\section{Group II mGluR Activation Induces a Long-Term Depression of Excitatory Transmission in the dBNST}

At many glutamatergic synapses in the CNS, mGluR activation can recruit a lasting reduction in synaptic efficacy. In particular, group II mGluR activation has been shown to reduce synaptic efficacy persistently at several different CNS synapses (Huang et al, 1999a; Otani et al, 1999; Lin et al, 2000; Kahn et al, 2001). While brief application of the group II mGluR agonist LY354740 produced only a transient depression of synaptic transmission, we find that more prolonged activation of the receptor produced a persistent depression of synaptic transmission in dBNST (Figure 5a). The effect is unlikely to be mediated simply by poor pharmacokinetics, as bath application of the antagonist LY341495 $(1 \mu \mathrm{M}) 30 \mathrm{~min}$ following washout of the agonist failed to reverse the depression (Figure $5 \mathrm{~b}$ ). This concentration of LY341495 was sufficient to abolish the effects of LY354740 when applied immediately prior to agonist application (Figure $4 \mathrm{~d}$ ).

\section{Group III mGluR Activation Depresses Glutamatergic Transmission in the dBNST}

To test the potential role of group III mGluRs in regulating glutamatergic transmission in the dBNST, we bathed slices with increasing concentrations of the group III mGluR agonist, L-AP4. At the maximal concentration tested $(1 \mathrm{mM}), \mathrm{L}-\mathrm{AP} 4$ induced a depression of EPSC amplitude to
$41.0 \pm 6.9 \%$ of the baseline amplitude that only partially reversed to $69.6 \pm 9.9 \%$ of baseline $40 \mathrm{~min}$ after washout (Figure 6a). No changes in postsynaptic properties were observed. The dose-response relationship suggests a low potency for L-AP4, since $1 \mathrm{mM}$ L-AP4 did not clearly saturate the effect (Figure $6 \mathrm{c}$ ). To begin to determine which subtypes of group III mGluRs may participate in regulating glutamatergic transmission in dBNST, we also utilized the mGluR8 specific agonist DCPG. $30 \mu \mathrm{M}$ DCPG elicited a depression of EPSC amplitude to $70.4 \pm 7.9 \%$ of the baseline amplitude (Figure 6b).

\section{Activation of Group II Receptors does not Enhance Group III mGluR-Mediated Inhibition}

Multiple brain regions provide glutamatergic input into the dBNST, including the BLA, subiculum, and prelimbic cortical areas. While both group II and group III mGluR activation robustly inhibits EPSCs in the dBNST, neither completely abolishes the response. To begin to determine whether group II and group III mGluRs act at the same synapses through the same mechanisms, we coapplied these agonists at the maximal concentrations we utilized. Coapplication of $1 \mu \mathrm{M}$ LY354740 (a saturating concentration based on the concentration-response curve) and $1 \mathrm{mM}$ L-AP4 for 5 min resulted in a depression of EPSC amplitude to $34.5 \pm 7.2 \%$ (Figure 7 ). The effect partially reversed to a magnitude of $64.9 \pm 11.2 \%$ baseline. The coapplication of LY354740 and L-AP4 did not significantly alter EPSCs 
compared with the effects of L-AP4 at the concentrations used $(34.5 \pm 7.2$ vs $41.0 \pm 6.9 \%$ of baseline for LY354740+ L-AP4 and L-AP4 alone, respectively; $p>0.05)$. Thus, these data suggest that the mGluRs mediating the actions of these drugs may be expressed on a common set of synapses.

\section{Group II and Group III mGluR Depression of EPSC Amplitude is Associated with Enhancement of Paired-Pulse Ratios in the dBNST}

To begin to determine the locus of the actions of group II and group III mGluRs in regulating EPSC amplitude, we
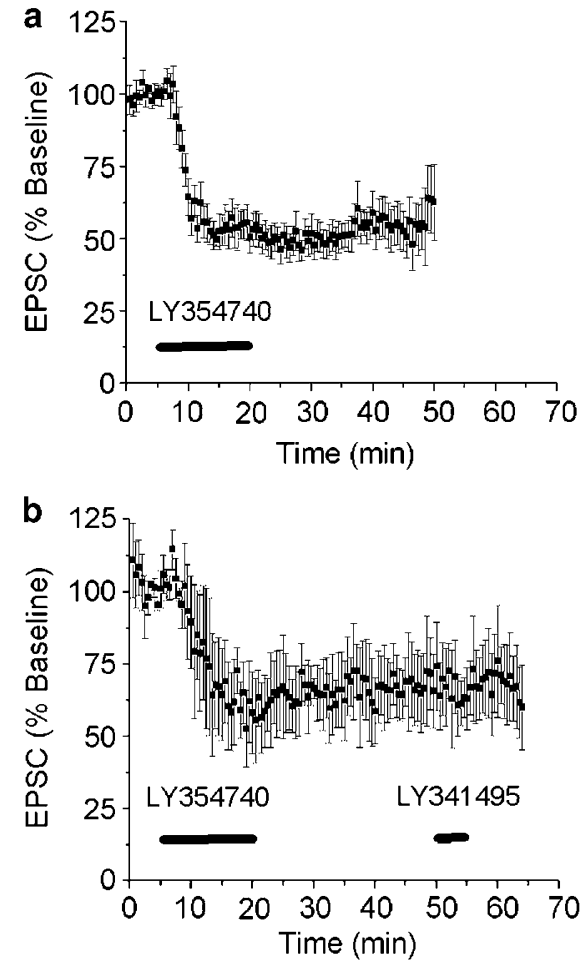

Figure 5 Group $\|$ mGluR activation induces LTD in the BNST. (a) Application of LY354740 (I $\mu \mathrm{M})$ for an extended time period (I $\mu \mathrm{M}$, $15 \mathrm{~min}$ ) resulted in a depression of synaptic transmission that persisted in the absence of the drug $(n=9)$. (b) Application of LY34I495 (I $\mu \mathrm{M})$ 30 min post-LY354740 washout fails to reverse depression of EPSC $(n=3)$. incorporated paired-pulse ratio (PPR) measurements in our experimental design. Alterations in PPR are classically interpreted as suggestive of a change in presynaptic function. As seen in Figure $8 \mathrm{a}, 5 \mathrm{~min}$ application of LY354740 caused a marginal increase in PPR. A more robust and persistent increase in PPR was seen with the longer application of LY354740 (Figure 8b). Interestingly, the enhancement of group II mGluR-mediated effects on PPR mirrored that of the inhibition of the EPSCs. Activation of group III mGluRs by L-AP4 also led to a long-lasting increase in PPR that mirrored the inhibition of the EPSCs (Figure 8c). As shown in Figure 8d, both LY354740 and L-AP4 significantly increased PPR.

\section{DISCUSSION}

The BNST, and in particular glutamatergic transmission within the BNST, is believed to be a critical substrate for stress/anxiety pathways. Metabotropic glutamate receptor ligands, in particular group II and group III mGluR agonists, produce anxiolytic effects on animal behavior in a variety of tasks (Klodzinska et al, 1999; Tatarczynska et al, 2002; Schoepp et al, 2003; Palucha et al, 2004); however to date, the sites of actions responsible for these effects are

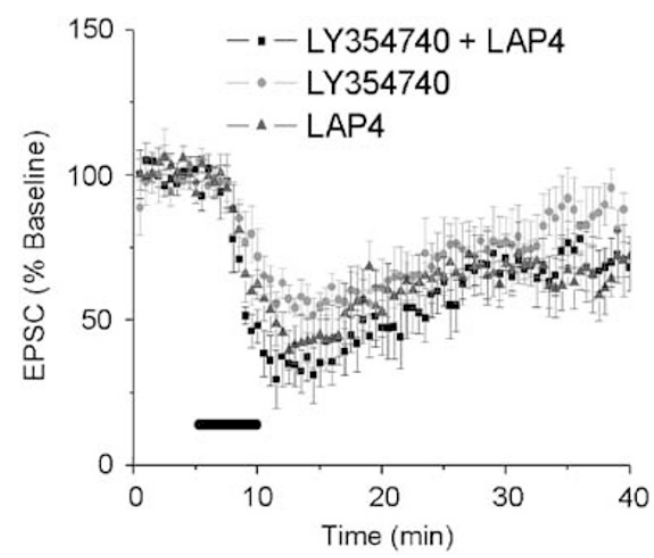

Figure 7 Group II receptor activation fails to enhance group III mediated inhibition of EPSCs in the BNST. Time course of effects of LY354740 ( I $\mu \mathrm{M})$, L-AP4 (I mM), and coapplication of the agonists for 5 min on EPSCs in the BNST $(n=4)$.
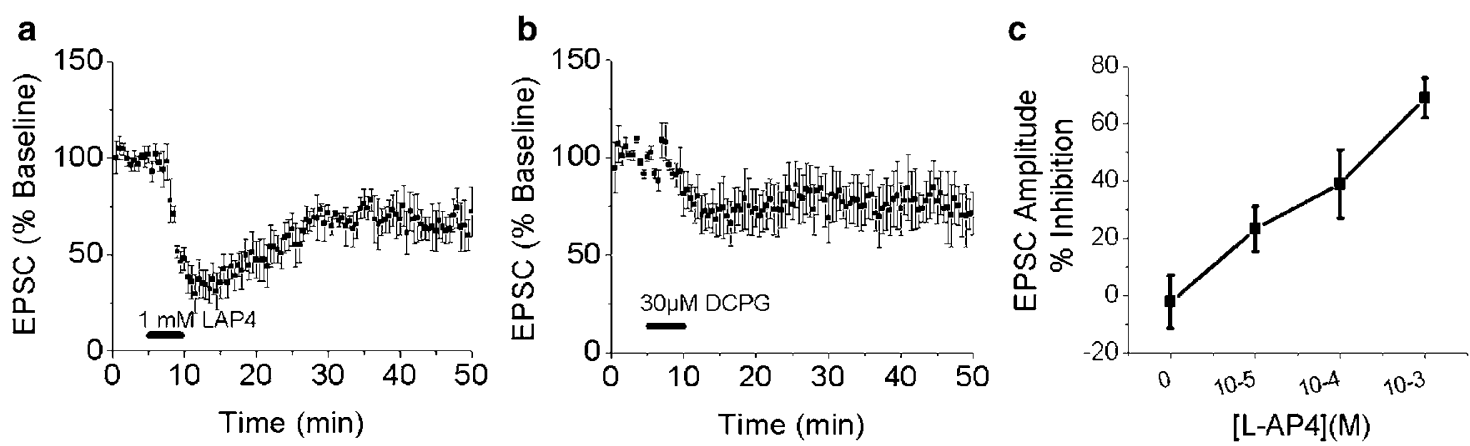

Figure 6 Group III mGluR activation inhibits EPSCs in the BNST. (a) I mM L-AP4 caused a lasting depression in synaptic transmission ( $n=6$ ). (b) Effects of $30 \mu \mathrm{M}$ DCPG on synaptic transmission in the BNST. (c) Effects of 10, $100 \mu \mathrm{M}$, and I mM L-AP4 on EPSC amplitude $(n=5-6)$. 

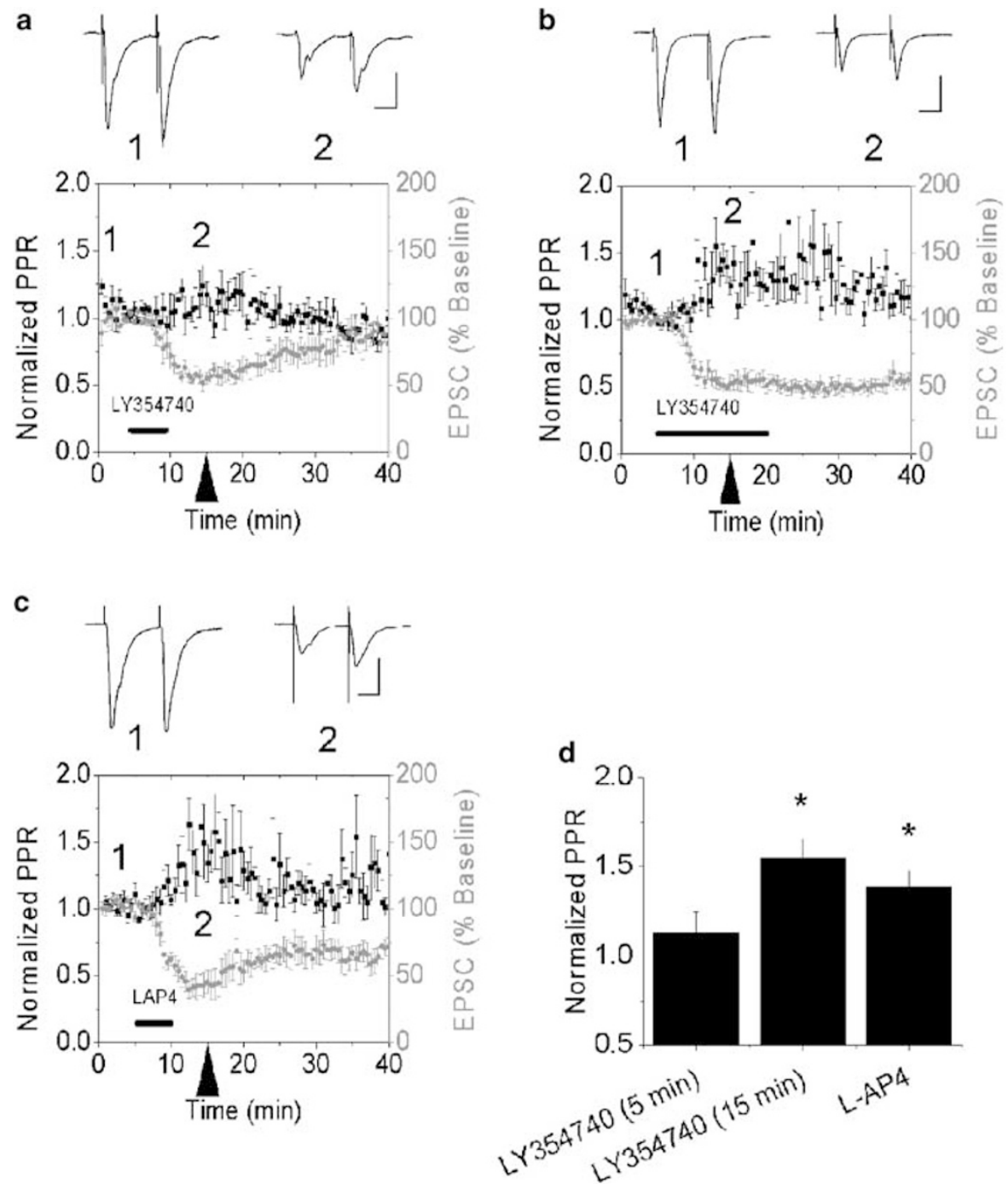

Figure 8 Group II or III mGluRs function has a presynaptic locus. (a) Time course of PPR from cells in which LY354740 was applied over 5 min ( $n=6$ ). Insets are representative traces from time points indicated for $a-c$. (b) Time course of PPR from cells in which LY354740 was applied over I5 min ( $n=9$ ). (c) Time course of PPR from cells in which I mM L-AP4 was applied $(n=6)$. (d) Graph of PPR at the initial peak depression of the EPSC. Arrow indicates time at which analysis was performed. Scales indicate $100 \mathrm{pA}$ and $20 \mathrm{~ms}$.

unknown. In this study, we report that fast glutamatergic transmission in the BNST of adult mice is depressed by these ligands.

Consistent with the function of group II mGluRs in other brain regions (Bushell et al, 1996; Macek et al, 1996; Kilbride et al, 1998), we find selective activation of group II mGluRs in the BNST can produce a reversible depression of synaptic transmission. We find that two group II mGluR selective agonists, DCG-IV and LY354740 (Schoepp et al, 1997), inhibited glutamate-dependent field potentials and EPSCs, and that this effect was blocked by LY341495 at concentrations selective for group II mGluRs. The effect of LY354740 on EPSCs is potent and concentration-dependent, with maximal depression elicited by $100 \mathrm{nM}$ LY354740. As DCG-IV has agonist activity at the NMDA receptor at higher concentrations (Uyama et al, 1997), we performed experiments with this compound in the presence of the NMDA receptor antagonist DL-AP5.
For the study of group III mGluRs, we also used two agonists, L-AP4 and DCPG. L-AP4, the most commonly used selective group III agonist has a high affinity for mGluR4/6/8 and a low affinity for mGluR7 (Cartmell and Schoepp, 2000). DCPG, a more recently described group III mGluR agonist, is a relatively specific mGluR8 agonist (Linden et al, 2003). The dose-response relationship for L-AP4 suggests the involvement of mGluR7, since high concentrations of L-AP4 did not produce saturating actions. Consistent with this idea, anatomical evidence points to the expression of mGluR7, with weaker, if any, expression of mGluR4 in dBNST (Kinzie et al, 1995; Ohishi et al, 1995; Kinoshita et al, 1998). However, significant effects were observed with low concentrations of L-AP4, suggesting the possible involvement of other group III mGluRs. Consistent with this, we find that the mGluR8 agonist DCPG also decreases excitatory transmission. At present, it is unclear where mGluR8 is localized within BNST. 


\section{Group II mGluRs Modulate Excitatory Transmission}

Group II mGluRs are located primarily presynaptically and function to modulate transmitter release (Shigemoto et al, 1996, 1997; Conn and Pin, 1997; Anwyl, 1999), although there is also evidence for the function of group II mGluRs postsynaptically (Otani et al, 2002). Group II mGluRs can couple to a variety of effector systems (Conn and Pin, 1997), including regulation of cAMP production, direct modulation of ion channels, and in some cases activation of PLC and PLD (Otani et al, 2002). Consistent with immunohistochemical evidence of the presence of mGluR2 and mGluR3 in the BNST (Ohishi et al, 1998; Tamaru et al, 2001), our data suggest group II mGluRs function to decrease excitatory transmission in this region. The depression of glutamatergic transmission by group II mGluR agonists that we observed was accompanied by marked alterations in PPR, suggesting that the actions of the group II mGluRs in this case is likely a presynaptic one.

Interestingly, we found that while brief application of the group II agonists produced a reversible depression of glutamatergic transmission, more prolonged activation of the receptors produced a persistent, likely presynaptically mediated, depression of synaptic transmission in the BNST. This persistent depression does not appear to be due to poor pharmacokinetics or a constitutively activated group II mGluR since late application of the antagonist LY341495 did not reverse the depressed EPSC.

Long-term depression (LTD) of excitatory transmission induced by activation of group II mGluRs has been reported in a number of brain regions. For example, group II mGluRdependent LTD has been demonstrated in the BLA (Lin et al, 2000), the nucleus accumbens (Robbe et al, 2002), the striatum (Kahn et al, 2001), and the mossy fiber-CA3 synapse (Kobayashi et al, 1996). In these regions, evidence suggests that the persistent depression is mediated presynaptically via a reduction in glutamate release. In contrast, thalamic inputs to the lateral nucleus of the amygdala (Heinbockel and Pape, 2000), as well as glutamatergic synapses in the dentate gyrus and medial prefrontal cortex (Huang et al, 1999b; Otani et al, 2002) undergo a group II mGluR-mediated LTD that appears to be postsynaptically elicited. The LTD that we observe in the BNST is associated with a persistent alteration in PPRs, suggesting that it may be mediated by presynaptic alterations in glutamate release. In contrast to group I mGluR LTD in the hippocampus (Palmer et al, 1997), yet similar to group II LTD in the striatum (Kahn et al, 2001), LTD in the BNST was not caused by slow washout of LY354740 or a constitutively activated receptor because application of the group II antagonist LY341495 during the washing period did not affect the magnitude of LTD.

\section{Group III mGluRs Modulate Excitatory Transmission in the BNST}

In addition to the effects of group II mGluR activation, the group III agonist L-AP4 clearly inhibited the synaptically evoked responses of BNST neurons. Like group II mGluRs, group III mGluRs are coupled to a variety of effectors, including inhibition of cAMP production, and direct modulation of ion channels (Conn and Pin, 1997).
As with the group II mGluR activation, we find that activation of group III mGluRs can elicit a lasting, presynaptically mediated depression of EPSCs in the BNST, suggesting that activation of group III mGluRs may also produce LTD in this region. Indeed, LTD requiring group III mGluRs has been observed at glutamatergic inputs on interneurons in CA3 (Laezza et al, 1999). Unfortunately, however, at present we cannot rule out the possibility that the persistent depression is a consequence of poor drug washout since antagonist development for group III mGluRs has lagged behind the other groups.

\section{Group II mGluR Activation Fails to Enhance Inhibitory Effects of Group III mGluR Activation}

Multiple mGluRs with different signaling cascades have been shown to function at the same synapses (Chen and van den Pol, 1998). We find that activation of group II or group III mGluRs does not completely block excitatory transmission in the BNST. We therefore hypothesized that either (1) the receptors function at differing afferent pathways or (2) there was incomplete modulation of glutamatergic transmission by activation of mGluRs at each synapse. In order to begin to test if group II and group III mGluRs act on different inputs or different signaling pathways we coapplied specific agonists. Activation of group II mGluRs did not enhance the inhibition induced by the group III agonist. This suggests the interesting possibilities that either these mGluRs function at a common pool of afferent inputs and/ or that they converge to some degree on common effector pathways. Future higher resolution anatomical studies combined with more mechanistic studies will be necessary to address these possibilities.

\section{Behavioral Relevance}

The present findings are consistent with the anxiolytic properties of agonists of group II and group III receptors. AMPA receptor antagonists directly injected into the BNST reduce potentiated startle responses (Walker and Davis, 1997), suggesting that dampening fast glutamatergic signaling in the BNST can produce anxiolytic responses. Thus, the depression of this transmission produced by group II and group III mGluR agonists that we observe in the present study would be predicted to have similar outcomes on behavior. Reduced glutamatergic drive within the BNST would likely decrease output to the stress and reward circuitry, potentially reducing recruitment of the HPA axis.

\section{CONCLUSIONS}

The BNST plays a critical role in the response to stress and anxiety through a mechanism that involves excitatory glutamatergic transmission. The present study has demonstrated that excitatory transmission in the BNST is modulated by activation of group II and group III mGluRs. Thus, mGluRs within the BNST represent a candidate therapeutic target for the treatment of anxiety disorders. Behavioral studies will be necessary to test this possibility. 


\section{ACKNOWLEDGEMENTS}

This work was supported by an NIAAA INIA pilot Grant (U01-AA13541). We thank Dr Jeff Conn for helpful discussions, and Dr Tom Kash and Dr Bob Matthews for critical reading of an earlier version of the manuscript.

\section{REFERENCES}

Anwyl R (1999). Metabotropic glutamate receptors: electrophysiological properties and role in plasticity. Brain Res Brain Res Rev 29: $83-120$.

Bushell TJ, Jane DE, Tse HW, Watkins JC, Garthwaite J, Collingridge GL (1996). Pharmacological antagonism of the actions of group II and III mGluR agonists in the lateral perforant path of rat hippocampal slices. Br J Pharmacol 117: $1457-1462$.

Capogna M (2004). Distinct properties of presynaptic group II and III metabotropic glutamate receptor-mediated inhibition of perforant pathway-CA1 EPSCs. Eur J Neurosci 19: 2847-2858.

Cartmell J, Schoepp DD (2000). Regulation of neurotransmitter release by metabotropic glutamate receptors. J Neurochem 75: 889-907.

Chen G, van den Pol AN (1998). Coexpression of multiple metabotropic glutamate receptors in axon terminals of single suprachiasmatic nucleus neurons. J Neurophysiol 80: 1932-1938.

Conn PJ, Pin JP (1997). Pharmacology and functions of metabotropic glutamate receptors. Annu Rev Pharmacol Toxicol 37: 205-237.

Davis M, Walker DL, Lee Y (1997). Amygdala and bed nucleus of the stria terminalis: differential roles in fear and anxiety measured with the acoustic startle reflex. Philos Trans $R$ Soc Lond Ser B Biol Sci 352: 1675-1687.

Delfs JM, Zhu Y, Druhan JP, Aston-Jones G (2000). Noradrenaline in the ventral forebrain is critical for opiate withdrawal-induced aversion. Nature 403: 430-434.

Dong HW, Swanson LW (2004). Organization of axonal projections from the anterolateral area of the bed nuclei of the stria terminalis. J Comp Neurol 468: 277-298.

Egli RE, Winder DG (2003). Dorsal and ventral distribution of excitable and synaptic properties of neurons of the bed nucleus of the stria terminalis. J Neurophysiol 90: 405-414.

Egli RE, Kash T, Choo K, Matthews RT, Savchenko V, Blakely R, Winder DG. Differential noradrenergic modulation of excitatory synaptic transmission in the bed nucleus of the stria terminalis. Neuropsychopharmacology, (in press).

Evans DI, Jones RS, Woodhall G (2000). Activation of presynaptic group III metabotropic receptors enhances glutamate release in rat entorhinal cortex. J Neurophysiol 83: 2519-2525.

Franklin KBJ, Paxinos G (1997). The Mouse Brain in Stereotaxic Coordinates. Academic Press: New York.

Georges F, Aston-Jones G (2002). Activation of ventral tegmental area cells by the bed nucleus of the stria terminalis: a novel excitatory amino acid input to midbrain dopamine neurons. J Neurosci 22: 5173-5187.

Grillon C, Cordova J, Levine LR, Morgan III CA (2003). Anxiolytic effects of a novel group II metabotropic glutamate receptor agonist (LY354740) in the fear-potentiated startle paradigm in humans. Psychopharmacology (Berl) 168: 446-454.

Heinbockel T, Pape HC (2000). Input-specific long-term depression in the lateral amygdala evoked by theta frequency stimulation. J Neurosci 20: RC68.

Helton DR, Tizzano JP, Monn JA, Schoepp DD, Kallman MJ (1998). Anxiolytic and side-effect profile of LY354740: a potent, highly selective, orally active agonist for group II metabotropic glutamate receptors. J Pharmacol Exp Ther 284: 651-660.
Herman JP, Cullinan WE (1997). Neurocircuitry of stress: central control of the hypothalamo-pituitary-adrenocortical axis. Trends Neurosci 20: 78-84.

Huang LQ, Rowan MJ, Anwyl R (1999a). Role of protein kinases A and $\mathrm{C}$ in the induction of mGluR-dependent long-term depression in the medial perforant path of the rat dentate gyrus in vitro. Neurosci Lett 274: 71-74.

Huang L, Rowan MJ, Anwyl R (1999b). Induction of long-lasting depression by (+)-alpha-methyl-4-carboxyphenylglycine and other group II mGlu receptor ligands in the dentate gyrus of the hippocampus in vitro. Eur J Pharmacol 366: 151-158.

Kahn L, Alonso G, Robbe D, Bockaert J, Manzoni OJ (2001). Group 2 metabotropic glutamate receptors induced long term depression in mouse striatal slices. Neurosci Lett 316: 178-182.

Kilbride J, Huang LQ, Rowan MJ, Anwyl R (1998). Presynaptic inhibitory action of the group II metabotropic glutamate receptor agonists, LY354740 and DCG-IV. Eur J Pharmacol 356: 149-157.

Kinoshita A, Shigemoto R, Ohishi H, van der Putten H, Mizuno N (1998). Immunohistochemical localization of metabotropic glutamate receptors, mGluR7a and mGluR7b, in the central nervous system of the adult rat and mouse: a light and electron microscopic study. J Comp Neurol 393: 332-352.

Kinzie JM, Saugstad JA, Westbrook GL, Segerson TP (1995). Distribution of metabotropic glutamate receptor 7 messenger RNA in the developing and adult rat brain. Neuroscience 69: 167-176.

Klodzinska A, Chojnacka-Wojcik E, Palucha A, Branski P, Popik P, Pilc A (1999). Potential anti-anxiety, anti-addictive effects of LY 354740 , a selective group II glutamate metabotropic receptors agonist in animal models. Neuropharmacology 38: 1831-1839.

Kobayashi K, Manabe T, Takahashi T (1996). Presynaptic longterm depression at the hippocampal mossy fiber-CA3 synapse. Science 273: 648-650.

Laezza F, Doherty JJ, Dingledine R (1999). Long-term depression in hippocampal interneurons: joint requirement for pre- and postsynaptic events. Science 285: 1411-1414.

Linden AM, Bergeron M, Baez M, Schoepp DD (2003). Systemic administration of the potent mGlu8 receptor agonist $(S)-3,4$ DCPG induces c-Fos in stress-related brain regions in wild-type, but not mGlu8 receptor knockout mice. Neuropharmacology 45: 473-483.

Linden AM, Johnson BG, Peters SC, Shannon HE, Tian M, Wang Y et al (2002). Increased anxiety-related behavior in mice deficient for metabotropic glutamate 8 (mGlu8) receptor. Neuropharmacology 43: 251-259.

Lin HC, Wang SJ, Luo MZ, Gean PW (2000). Activation of group II metabotropic glutamate receptors induces long-term depression of synaptic transmission in the rat amygdala. J Neurosci 20: 9017-9024.

Macek TA, Winder DG, Gereau RWt, Ladd CO, Conn PJ (1996). Differential involvement of group II and group III mGluRs as autoreceptors at lateral and medial perforant path synapses. J Neurophysiol 76: 3798-3806.

Neugebauer V, Keele NB, Shinnick-Gallagher P (1997). Loss of long-lasting potentiation mediated by group III mGluRs in amygdala neurons in kindling-induced epileptogenesis. J Neurophysiol 78: 3475-3478.

Neugebauer V, Zinebi F, Russell R, Gallagher JP, ShinnickGallagher P (2000). Cocaine and kindling alter the sensitivity of group II and III metabotropic glutamate receptors in the central amygdala. J Neurophysiol 84: 759-770.

Ohishi H, Akazawa C, Shigemoto R, Nakanishi S, Mizuno N (1995). Distributions of the mRNAs for L-2-amino-4-phosphonobutyrate-sensitive metabotropic glutamate receptors, mGluR4 and mGluR7, in the rat brain. J Comp Neurol 360: 555-570.

Ohishi H, Neki A, Mizuno N (1998). Distribution of a metabotropic glutamate receptor, mGluR2, in the central nervous system of the 
rat and mouse: an immunohistochemical study with a monoclonal antibody. Neurosci Res 30: 65-82.

Otani S, Auclair N, Desce JM, Roisin MP, Crepel F (1999). Dopamine receptors and groups I and II mGluRs cooperate for long-term depression induction in rat prefrontal cortex through converging postsynaptic activation of MAP kinases. J Neurosci 19: $9788-9802$.

Otani S, Daniel H, Takita M, Crepel F (2002). Long-term depression induced by postsynaptic group II metabotropic glutamate receptors linked to phospholipase $\mathrm{C}$ and intracellular calcium rises in rat prefrontal cortex. J Neurosci 22: 3434-3444.

Palmer MJ, Irving AJ, Seabrook GR, Jane DE, Collingridge GL (1997). The group I mGlu receptor agonist DHPG induces a novel form of LTD in the CA1 region of the hippocampus. Neuropharmacology 36: 1517-1532.

Palucha A, Tatarczynska E, Branski P, Szewczyk B, Wieronska JM, Klak K et al (2004). Group III mGlu receptor agonists produce anxiolytic- and antidepressant-like effects after central administration in rats. Neuropharmacology 46: 151-159.

Phelix CF, Liposits Z, Paull WK (1992). Monoamine innervation of bed nucleus of stria terminalis: an electron microscopic investigation. Brain Res Bull 28: 949-965.

Phillipson OT (1979). The cytoarchitecture of the interfascicular nucleus and ventral tegmental area of Tsai in the rat. J Comp Neurol 187: 85-98.

Rainnie DG (1999). Neurons of the bed nucleus of the stria terminalis (BNST). Electrophysiological properties and their response to serotonin. Ann NY Acad Sci 877: 695-699.

Robbe D, Bockaert J, Manzoni OJ (2002). Metabotropic glutamate receptor 2/3-dependent long-term depression in the nucleus accumbens is blocked in morphine withdrawn mice. Eur $J$ Neurosci 16: 2231-2235.

Rush AM, Wu J, Rowan MJ, Anwyl R (2001). Activation of group II metabotropic glutamate receptors results in long-term potentiation following preconditioning stimulation in the dentate gyrus. Neuroscience 105: 335-341.

Scaccianoce S, Matrisciano F, Del Bianco P, Caricasole A, Di Giorgi Gerevini V, Cappuccio I et al (2003). Endogenous activation of group-II metabotropic glutamate receptors inhibits the hypothalamic-pituitary-adrenocortical axis. Neuropharmacology 44: $555-561$.

Schoepp DD, Johnson BG, Wright RA, Salhoff CR, Mayne NG, Wu $S$ et al (1997). LY354740 is a potent and highly selective group II metabotropic glutamate receptor agonist in cells expressing human glutamate receptors. Neuropharmacology 36: 1-11.

Schoepp DD, Wright RA, Levine LR, Gaydos B, Potter WZ (2003). LY354740, an mGlu2/3 receptor agonist as a novel approach to treat anxiety/stress. Stress 6: 189-197.
Schrader LA, Tasker JG (1997). Presynaptic modulation by metabotropic glutamate receptors of excitatory and inhibitory synaptic inputs to hypothalamic magnocellular neurons. J Neurophysiol 77: 527-536.

Shaham Y, Erb S, Stewart J (2000). Stress-induced relapse to heroin and cocaine seeking in rats: a review. Brain Res Brain Res Rev 33: 13-33.

Shigemoto R, Kinoshita A, Wada E, Nomura S, Ohishi H, Takada $M$ et al (1997). Differential presynaptic localization of metabotropic glutamate receptor subtypes in the rat hippocampus. J Neurosci 17: 7503-7522.

Shigemoto R, Kulik A, Roberts JD, Ohishi H, Nusser Z, Kaneko T et al (1996). Target-cell-specific concentration of a metabotropic glutamate receptor in the presynaptic active zone. Nature 381: 523-525.

Tamaru Y, Nomura S, Mizuno N, Shigemoto R (2001). Distribution of metabotropic glutamate receptor mGluR3 in the mouse CNS: differential location relative to pre- and postsynaptic sites. Neuroscience 106: 481-503.

Tatarczynska E, Palucha A, Szewczyk B, Chojnacka-Wojcik E, Wieronska J, Pilc A (2002). Anxiolytic- and antidepressant-like effects of group III metabotropic glutamate agonist $(1 S, 3 R, 4 S)-1$ aminocyclopentane-1,3,4-tricarboxylic acid (ACPT-I) in rats. Pol J Pharmacol 54: 707-710.

Tizzano JP, Griffey KI, Schoepp DD (2002). The anxiolytic action of mGlu2/3 receptor agonist, LY354740, in the fear-potentiated startle model in rats is mechanistically distinct from diazepam. Pharmacol Biochem Behav 73: 367-374.

Uyama Y, Ishida M, Shinozaki H (1997). DCG-IV, a potent metabotropic glutamate receptor agonist, as an NMDA receptor agonist in the rat cortical slice. Brain Res 752: 327-330.

Walker DL, Davis M (1997). Double dissociation between the involvement of the bed nucleus of the stria terminalis and the central nucleus of the amygdala in startle increases produced by conditioned versus unconditioned fear. J Neurosci 17: 9375-9383.

Walker DL, Toufexis DJ, Davis M (2003). Role of the bed nucleus of the stria terminalis versus the amygdala in fear, stress, and anxiety. Eur J Pharmacol 463: 199-216.

Weitlauf C, Egli RE, Grueter BA, Winder DG (2004). Highfrequency stimulation induces ethanol-sensitive long-term potentiation at glutamatergic synapses in the dorsolateral bed nucleus of the stria terminalis. J Neurosci 24: 5741-5747.

Wu J, Rowan MJ, Anwyl R (2004). An NMDAR-independent LTP mediated by group II metabotropic glutamate receptors and $\mathrm{p} 42 /$ 44 MAP kinase in the dentate gyrus in vitro. Neuropharmacology 46: $311-317$ 